\title{
Large Intestinal Mucositis
}

National Cancer Institute

\section{Source}

National Cancer Institute. Large Intestinal Mucositis. NCI Thesaurus. Code C78409.

An inflammatory process affecting the mucous membrane of the large intestine. 